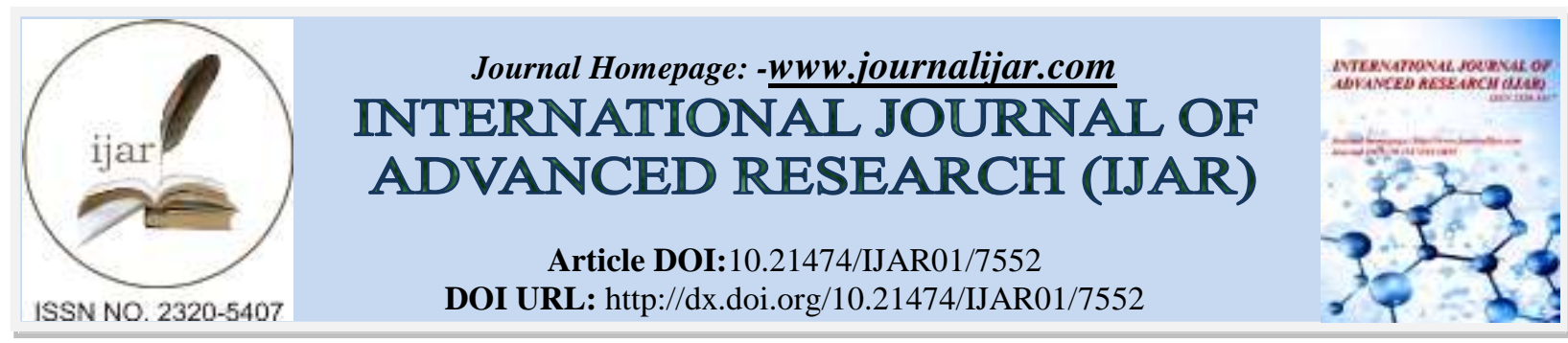

RESEARCH ARTICLE

\title{
A STUDY ON THE COMPRESSIVE \& FLEXURAL STRENGTH BEHAVIOR OF STEEL FIBER REINFORCED CONCRETE BEAM.
}

\author{
Nafisa Tabassum ${ }^{1}$, Pranta Biswas ${ }^{2}$, Dr. Md. Saiful Islam ${ }^{3}$ and Dr. Md. Moinul Islam ${ }^{3}$. \\ 1. Lecturer, Department of Civil Engineering, CUET, Bangladesh. \\ 2. Student, Department of Civil Engineering, CUET, Bangladesh. \\ 3. Professor, Department of Civil Engineering, CUET, Bangladesh.
}

\section{Manuscript Info Abstract}

\section{(...........................}

Manuscript History

Received: 13 June 2018

Final Accepted: 15 July 2018

Published: August 2018

\begin{abstract}
In Steel Fiber Reinforced Concrete (SFRC), steel fiber is added to concrete due to its ability to restrict the growth of cracks and thus changing the brittle mode of composite to a strong cement matrix with superior crack resistance. This paper presents an experimental program to investigate the compressive \& flexural strength characteristics of concrete with or without steel fibers. A total of 54 nos. $100 \mathrm{~mm}$ concrete cube specimens \& 44 nos. $100 \mathrm{~mm}$ x $100 \mathrm{~mm}$ x $500 \mathrm{~mm}$ concrete beam specimens were cast from M25 concrete with varying fiber volume fraction $(1.0,1.5,2.0 \& 2.5 \%)$ and two different aspect ratios $(50 \& 70)$. Required nos. of plain concrete specimens were also cast from the same concrete mix to compare the strength characteristics of plain and fiber reinforced concrete and to predict the effect of fiber inclusion. The result showed that both compressive and flexural strength of steel fiber reinforced concrete increased with the inclusion of steel fiber, the maximum being found that at $1.5 \%$ \& $2 \%$ steel fiber content for compressive \& flexural strength respectively and for aspect ratio of 70 . Also, the cracking/failure pattern of SFRC specimens showed improved ductility over that of plain concrete.
\end{abstract}

Copy Right, IJAR, 2018,. All rights reserved.

\section{Introduction:-}

Concrete being the most widely used construction material has been undergoing changes as a material and technology. Due to the growing demand of performance and durability of concrete, there has been a continuous search for upgrading the properties of concrete. High performance concrete, fiber reinforced concrete, selfcompacting concrete are a few examples of the outcome of the same. It is well known that plain concrete is weak in tension and brittle in nature. A growing tensile crack in plain concrete can very soon lead to failure and the presence of reinforcement resists the tensile stresses thereby enabling it to be used as structural members. An alternative to increasing the load carrying capacity of concrete in tension is the addition of fibers well dispersed in concrete to bridge the microcracks that develop in concrete. There are numerous fiber types available for commercial and experimental use. The basic fiber categories are steel, synthetic and natural fiber material. (Shende, A.M. et al., 2011).

Historically fibers have been used to reinforce brittle materials since ancient times. Straws were used to reinforce sun baked bricks; horsehair was used to reinforce plaster. More recently, asbestos fibers are used to reinforce 
Portland cement. Even though reinforcing a brittle matrix with discrete fibers is an age-old concept, modern-day use of fibers in concrete started in the early 1960s. In the beginning, only straight steel fibers were used. The major improvement occurred in the areas of ductility and fracture toughness, even though flexural strength increases were also reported. Romualdi et al. (1963) in early 1960's presented the first significant steps towards development of steel fiber reinforced concrete (SFRC). Although patents have been granted since the turn of the century for various methods of reinforcing concrete with steel, development of SFRC technology did not progress much until the late 1950's. Since that time, steel fibers have been optimized to some extent for incorporation into concrete. Also, mixing, placing, consolidating, and finishing techniques employed in SFRC have been improved. (Shende, A.M. et al., 2011)

\section{Steel Fiber Reinforced Concrete:-}

SFRC is produced using the conventional hydraulic cements, fine and coarse aggregates, water, and SFs. American concrete institution (ACI 544.IR, 1996) defines SFs as discrete, short lengths of steel having aspect ratio (ratio of length to diameter) in the range of 20 to 100 with any of the several cross-section which are sufficiently small to be easily and randomly dispersed in fresh concrete mix using conventional mixing procedures. To enhance the workability and stability of SFRC, super plasticizers (chemical admixtures) may also be added into the concrete mix (Behbahani et al., 2011).

The behavior of SFRC can be classified into three groups according to its application, fiber volume percentage and fiber effectiveness: Very low volume fraction of SFs (less than $1 \%$ per volume of concrete), which has been used for many years to control plastic shrinkage and as pavement reinforcement. Moderate volume fraction of SFs ( $1 \%$ to $2 \%$ per volume of concrete) which can improve modulus of rupture (MOR), flexural toughness, impact resistance and other desirable mechanical properties of concrete. High volume fraction of SFs (more than $2 \%$ per volume of concrete) used for special applications such as impact and blast resistance structure; these include SIFCON (Slurry Infiltrated Fiber Concrete), SIMCON (Slurry Infiltrated Mat Concrete) (Behbahani et al., 2011).

In most cases, SFs may act as secondary reinforcement used along with conventional steel bars or prestressing strands as the main reinforcement. In the class of high volume fraction of SFs (more than $2 \%$ per volume of concrete), the SFs have excellent mechanical properties and can be used without other continuous reinforcement; however, these composite materials are often suited for highly specialized applications due to the limitations associated with processing and cost (Behbahani et al., 2011).

\section{Effects of Steel Fibers in Concrete:-}

Fibers are usually used in concrete to control cracking due to both plastic shrinkage and drying shrinkage. They also reduce the permeability of concrete and thus reduce bleeding of water. Some types of fibers produce greater impact, abrasion and shatter resistance in concrete. Generally fibers do not increase the flexural strength of concrete and so cannot replace moment resisting or structural steel reinforcement. Indeed, some fibers actually reduce the strength of concrete. The amount of fibers added to the concrete mix is expressed as a percentage of total volume of the composite (concrete and fibers), termed volume fraction (Vf) that typically ranges from 0.1 to $3 \%$. Aspect ratio (1/d) is calculated by dividing fiber length (l) by its diameter (d). For fibers with a non-circular cross section, an equivalent diameter is used for the calculation of aspect ratio. If the modulus of elasticity of the fiber is higher than the matrix (concrete or mortar binder), they help to carry the load by increasing the tensile strength of the material. Increase in the aspect ratio $(1 / \mathrm{d})$ of the fiber usually segments the flexural strength and the toughness of the matrix. However, fibers which are too long tend to form ball in the mix and create workability problems. Some recent research findings indicate that using fibers in concrete has limited effect on the impact resistance of the materials. The results also indicate that the use of micro fibers offers better impact resistance compared with the longer fibers (Rana, A., 2013). Many researchers have already experimented the influence of the steel fibers on concrete properties [7],[8],[9],[10],[11],[12],[13]\&[14].

\section{Need For Present Study:-}

Although concrete is recognized as widely used construction material, it's application is limited due to some inherent properties such as low tensile strength, low strength to weight ratio, brittle nature, liable to cracking etc. In recent decades, fibers have gained popularity for use in concrete due to its certain special features. Inclusion of steel fibers can overcome the brittle failure of plain concrete and principle reason for incorporating fibers into concrete is to improve the properties of concrete such as toughness, compressive strength, tensile strength, flexural strength, shock resistance and fatigue resistance. In present study, steel fiber has been considered to reinforce concrete. 
The main objective of this study was to observe the compressive and flexural strength behavior of SFRC specimens. The specific objectives include the predictions of strength behavior of SFRC specimens cast using different volume fractions \& aspect ratios of steel fibers. The load deflection behaviors of various SFRC specimens were studied to predict the ductile response under increasing load. A number of plain concrete specimens were also cast to compare the effectiveness of fiber inclusion in improving the brittle nature of plain concrete.

\section{Experimental Program:-}

An experimental program was made by selecting the different parameters/variables as per need of the study. The followings are the materials used, their properties, experimental techniques etc.

\section{Materials \& Properties:-}

Cement:-

Ordinary Portland cement (Royal brand) was used for the preparation of concrete. Table-1 shows the properties of cement used.

Table-1:- Properties of Cement

\begin{tabular}{|c|c|c|c|}
\hline Features & Item & Test Results & Standard Value \\
\hline \multirow{5}{*}{$\begin{array}{l}\text { Physical } \\
\text { Properties }\end{array}$} & Fineness & $96 \%$ & $>95 \%$ \\
\hline & Specific Gravity & 3.15 & - \\
\hline & Standard Consistency & $25.40 \%$ & - \\
\hline & Initial Setting Time & $65 \mathrm{~min}$ & $>45 \mathrm{~min}$ \\
\hline & Final Setting Time & $190 \mathrm{~min}$ & $<420 \mathrm{~min}$ \\
\hline \multirow{10}{*}{$\begin{array}{c}\text { Chemical } \\
\text { Compositions } \\
(\%)\end{array}$} & $\mathrm{SiO}_{2}$ & 22 & $17-25$ \\
\hline & $\mathrm{Al}_{2} \mathrm{O}_{3}$ & 5.5 & $3-8$ \\
\hline & $\mathrm{Fe}_{2} \mathrm{O}_{3}$ & 3.4 & $0.5-6$ \\
\hline & $\mathrm{MgO}$ & 2.6 & $0.1-4$ \\
\hline & $\mathrm{SO}_{3}$ & 2 & $1-3$ \\
\hline & $\mathrm{CaO}$ & 62.8 & $60-67$ \\
\hline & $\mathrm{Na}_{2} \mathrm{O}$ & 0.4 & $0.4-1.3$ \\
\hline & $\mathrm{K}_{2} \mathrm{O}$ & 0.7 & $0.3-1$ \\
\hline & Solid Content & - & $0.3-0.5$ \\
\hline & Loss on Ignition & 0.51 & $1.8-2$ \\
\hline
\end{tabular}

Fine \& Coarse Aggregates:-

The fine aggregate used was natural sand passing through $4.75 \mathrm{~mm}$ sieve. Sand was collected from local source. Coarse aggregates obtained from crushed stones having nominal size of $19 \mathrm{~mm}$ were used in the present study.

Table-2 shows the properties of the fine \& coarse aggregate.

Table-2:- Properties of aggregates

\begin{tabular}{|c|c|c|c|}
\hline \multicolumn{2}{|c|}{ Fine Aggregate } & \multicolumn{2}{c|}{ Coarse Aggregate } \\
\hline Property & Value & Property & Value \\
\hline Specific Gravity & 2.1 & Specific Gravity & 2.4 \\
\hline Unit Weight & $1686 \mathrm{~kg} / \mathrm{m}^{3}$ & Unit Weight & $1512 \mathrm{~kg} / \mathrm{m}^{3}$ \\
\hline Absorption Capacity & $2.8 \%$ & Absorption Capacity & $0.85 \%$ \\
\hline Moisture Content & $0.2 \%$ & Moisture Content & $0.4 \%$ \\
\hline Fineness modulus & 1.5 & & \\
\hline
\end{tabular}

\section{Steel Fibers:-}

Locally available thin straight steel wires (Diamond Brand, G.I Wire) were used in this study. The wires were cut into various lengths as per aspect ratio. Table-3 shows the details of steel fiber.

Table 3:- Properties of steel fibers

\begin{tabular}{|c|c|c|c|c|c|}
\hline Shape & Appearance & $\begin{array}{c}\text { Gauge } \\
\text { No. }\end{array}$ & $\begin{array}{c}\text { Diameter } \\
(\mathrm{mm})\end{array}$ & $\begin{array}{c}\text { Effective } \\
\text { Length } \\
(\mathrm{mm})\end{array}$ & $\begin{array}{c}\text { Aspect } \\
\text { ratio } \\
(\mathrm{L} / \mathrm{D})\end{array}$ \\
\hline
\end{tabular}




\begin{tabular}{|l|l|l|l|l|l|}
\hline Straight \& Circular & \multirow{2}{*}{ Clear \& Bright } & \multirow{2}{*}{$\# 22$} & \multirow{2}{*}{0.68} & 34 & 50 \\
\cline { 4 - 6 } & & & & 47.6 & 70 \\
\hline
\end{tabular}

Water:-

Potable water (tap water) was used for mixing and curing all concrete specimens under investigation.

\section{Experimental Methodology:-}

Sample Preparation:-

The constituent materials of concrete, viz., cement, sand and aggregates were tested as per requirement of Mix design according to ACI 211.1-91. Mix design information for M25 grade concrete is given in Table-4. A total of 54 nos. $100 \mathrm{~mm}$ cubical concrete specimens and 44 nos. of $100 \mathrm{~mm}$ x $100 \mathrm{~mm}$ x $500 \mathrm{~mm}$ concrete beam specimens were cast with varying volume fraction $(1.0,1.5,2.0 \& 2.5 \%)$ and two different aspect ratios $(50 \& 70)$.

Table 4:- Mix proportion for $1 \mathrm{~m}^{3} 25 \mathrm{MPa}$ fresh concrete

\begin{tabular}{|c|c|}
\hline \multicolumn{2}{|c|}{ M25 Grade } \\
\hline Materials & Quantity \\
\hline Cement & $421 \mathrm{~kg} / \mathrm{m}^{3}$ \\
\hline Fine Aggregate & $711 \mathrm{~kg} / \mathrm{m}^{3}$ \\
\hline Coarse Aggregate & $1006 \mathrm{~kg} / \mathrm{m}^{3}$ \\
\hline Water Content & $207 \mathrm{~kg} / \mathrm{m}^{3}$ \\
\hline W/C & 0.49 \\
\hline
\end{tabular}

The molds were filled with concrete mix and vibration was given to the molds using nozzle vibrator. The top surface of the cubes and beams was finished as smooth by trowel. Demolding was done after 24 hours and the specimens were cured under normal tap water at room temperature. After specific curing periods i.e. 14 days and 28 days, the specimens were removed from curing tank for testing.

\section{Testing of Specimens:-}

Two types of strength tests i.e. compressive and flexural strength tests were performed to assess the performance of SFRC. $100 \mathrm{~mm}$ cubes were used for compression strength test \& $100 \mathrm{~mm}$ x $100 \mathrm{~mm}$ x $500 \mathrm{~mm}$ beams for flexural strength test. Both compressive \& flexural strength tests were carried out as per IS 516-1959. For flexural strength test, the beam specimens were supported symmetrically over a span of $400 \mathrm{~mm} \&$ subjected to two point loading till failure of the specimen. The deflection at the center of the beam was measured with sensitive dial gauge on testing machine. In addition, load-deflection information were recorded during the flexural strength test of beam specimen.

\section{Results \& Discussion:-}

After curing of all specimens for different curing periods, specimens were tested for compressive and flexural strength test in compressive testing and beam testing machine respectively. For each data, three cube specimens and two beam specimens were tested and average strengths were reported.The strength values of specimens for different percentages of steel fibers \& aspect ratios were recorded. The results are shown below in tabular and graphical forms.

\section{Visual Examination:-}

The photographs of the test specimens shown below can give idea about the influence of fiber inclusion in concrete specimen at different volume fractions.

Plate-1\&2 shows the failure/cracking pattern of plain \& SFRC specimens under compression and Plate-3 \& 4 shows the same for flexure specimens. For compressive strength, it is seen that formation of crack is higher in plain concrete specimen (Plate-1) than SFRC specimen (Plate-2). When tested for flexural strength, the plain concrete specimen failed at low loads \& broken into two pieces (Plate-3). In SFRC specimen, the cracks formed were limited in width \& in a gradual manner indicating improved ductility of SFRC due to the addition of fibers over control concrete (Plate-4). 


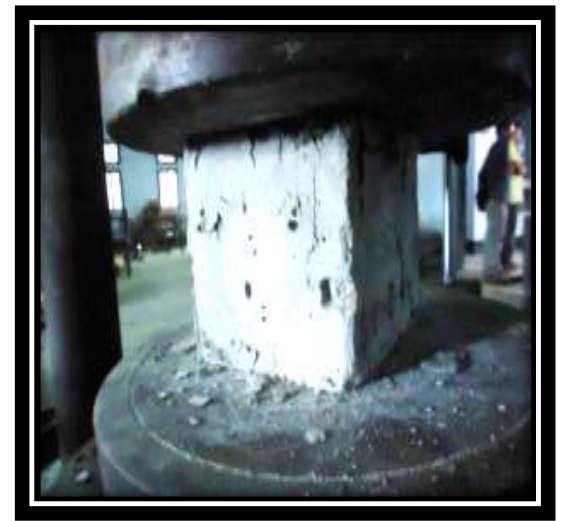

Plate-1:- Compressive strength test of plain concrete cubical specimen

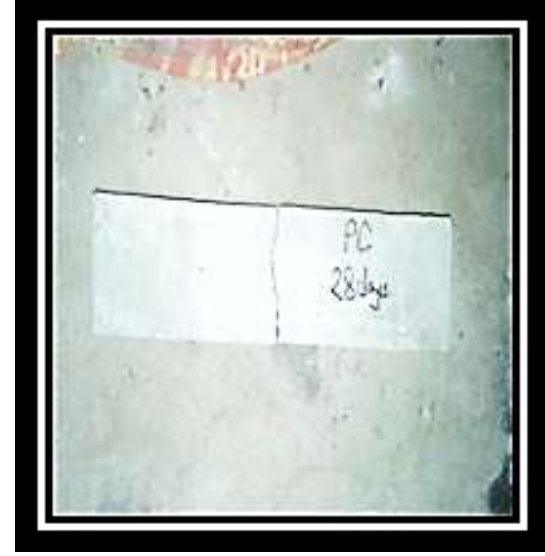

Plate-3:- Flexural strength test of plain concrete beam specimen

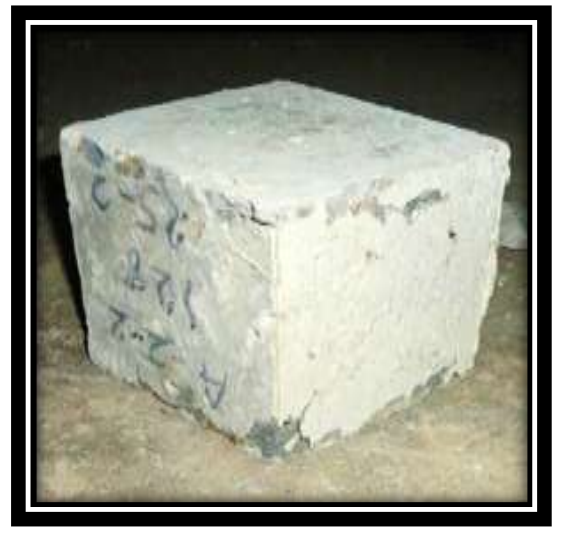

Plate-2:- Compressive strength test of SFRC cubical specimen

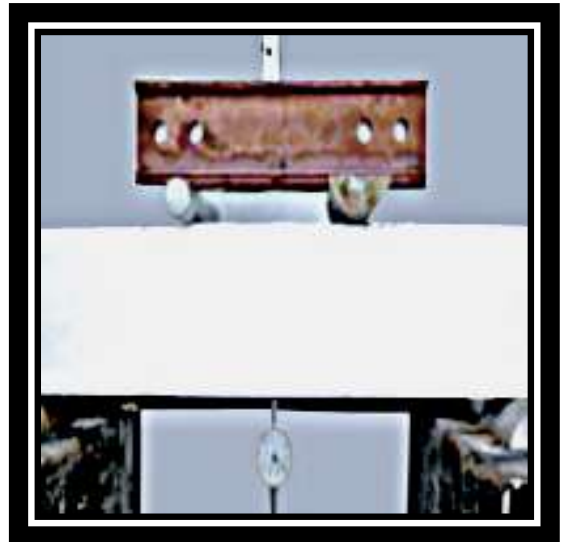

Plate-4:- Flexural strength test of SFRC beam specimen

\section{Experimental Test Results:-}

The 14 and 28 days compressive strength of plain and SFRC specimens obtained from tests of cube specimens are presented in Table-5. Also, the flexural strength of the beam specimens have been shown in the same table. At the same time, the compressive strength values of the specimens have been shown by graphical presentation in Fig- $1 \&$ 2 for the ease of understanding \& interpretation.

Table-5:- compressive \& flexural strength of plain and SFRC specimens at various curing ages

\begin{tabular}{|c|c|c|c|c|c|}
\hline \multirow{2}{*}{$\begin{array}{l}\text { 1) Aspect } \\
\text { Ratio }\end{array}$} & \multirow{2}{*}{$\begin{array}{r}\text { 2) Volume } \\
\text { Fractions (\%) }\end{array}$} & \multicolumn{2}{|c|}{ 3) Compressive Strength (MPa) } & \multicolumn{2}{|c|}{ 4) Flexural Strength (MPa) } \\
\hline & & 5) 14 days & 6) 28 days & 7) 14 days & 8) 28 days \\
\hline 0 & 0 & 22.10 & 28.30 & 3.00 & 3.76 \\
\hline \multirow[t]{4}{*}{50} & 1.0 & 24.40 & 29.50 & 4.55 & 5.33 \\
\hline & 1.5 & 27.40 & 33.50 & 4.70 & 5.48 \\
\hline & 2.0 & 23.60 & 30.60 & 6.00 & 6.22 \\
\hline & 2.5 & 23.10 & 29.20 & 4.52 & 5.28 \\
\hline \multirow[t]{4}{*}{70} & 1.0 & 24.50 & 31.30 & 4.52 & 5.38 \\
\hline & 1.5 & 28.30 & 35.20 & 5.28 & 6.50 \\
\hline & 2.0 & 25.40 & 32.60 & 5.38 & 6.55 \\
\hline & 2.5 & 24.30 & 31.60 & 5.02 & 6.48 \\
\hline
\end{tabular}




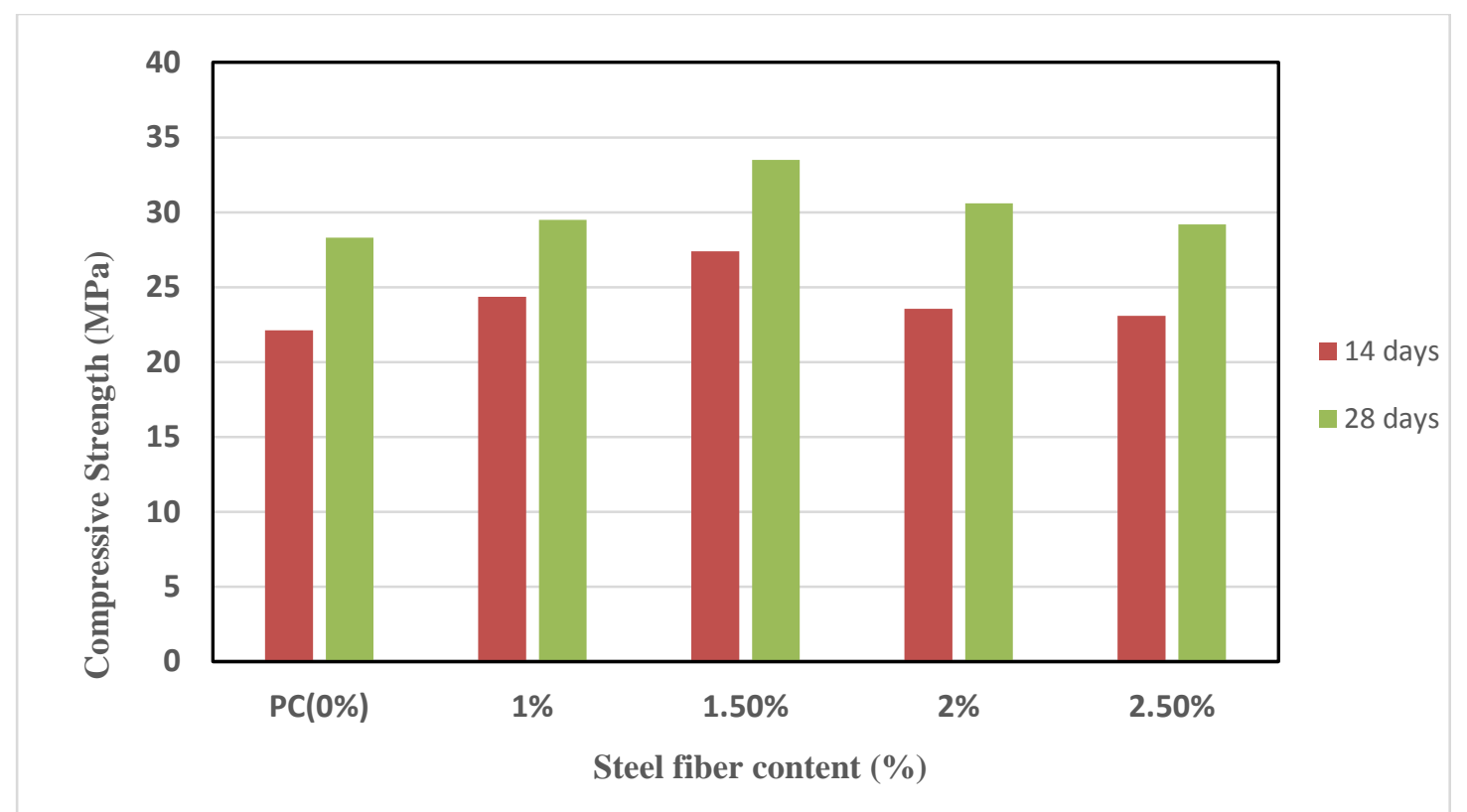

Fig-1:-Bar graph for variation of compressive strength of concrete specimens with various steel fiber content cured at different ages (AR: 50)

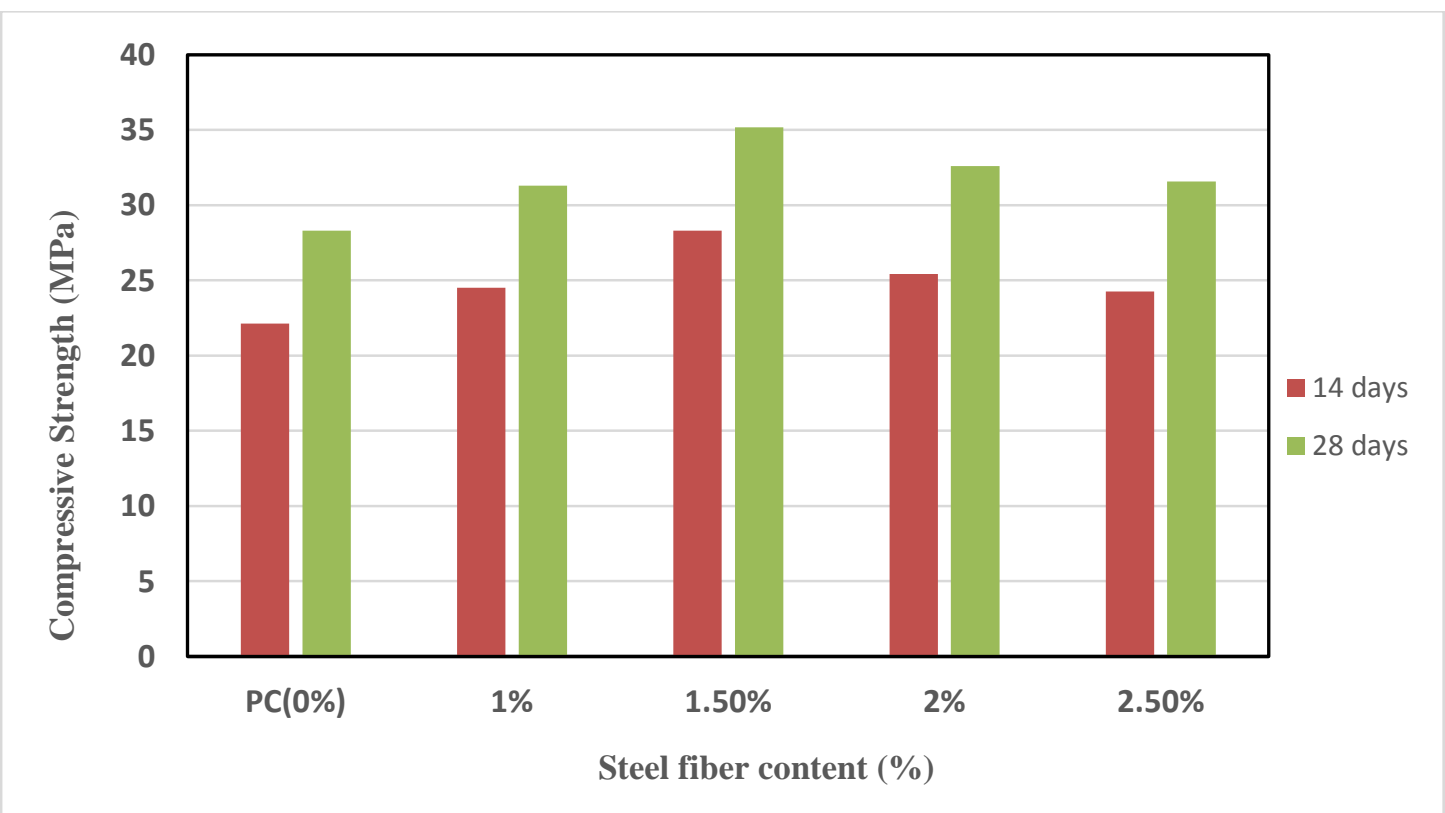

Fig-2:- Bar graph for variation of compressive strength of concrete specimens with various steel fiber content cured at different ages (AR: 70).

From the test results, it is seen that for a particular aspect ratio, both the compressive \& flexural strength of the SFRC specimens increases with the increase of the fiber content up to a certain limit $\&$ then decreases. After 28 days, the maximum compressive strength is found to be $35.20 \mathrm{MPa}$ at $1.5 \%$ steel fiber content whereas the maximum flexural strength is observed as $6.55 \mathrm{MPa}$ at $2.0 \%$ fiber content. The similar trend is also noticed at earlier age of curing i.e. at 14 days. However, after 28 days of curing, when compared to the strength of plain concrete, the increase in compressive strength for SFRC specimens is reported to vary in the range of 4 to $24 \%$. Again for the same curing age, the flexural strength of SFRC specimens increases from 40 to $70 \%$ as compared to plain concrete specimens. Thus it is clear that the strength improvement of SFRC is more in case of flexure in comparison to compressive strength for the identical conditions. It is due to the fact that steel fibers in SFRC act as a crack arrestor 
restricting the formation \& development of cracks and thus transforming an inherently brittle matrix into a strong composite with superior tension resistance $\&$ improved ductility that increases both flexural $\&$ compressive strength of concrete. Also of the two aspect ratios considered, the strength improvement is observed to higher in case of higher aspect ratio for both 14 days \& 28 days curing period. The increase in compressive strength was about $6 \%$ as the aspect ratio changes from 50 to 70 . Considering flexural strength, the corresponding increase was reported as about $11 \%$.

The load $(\mathrm{kN})$ vs deflection $(\mathrm{mm})$ data for SFRC beams cast using various volume fractions of steel, aspect ratio \& cured at two different ages are presented in Table 6 to 7. Also for the ease of understanding, these data/information are graphically presented through Fig 3 to 6 . A sensitive dial gauge was placed at the mid-section of beam for recording the deflection with the increase of load till failure of the beam.

Table-6:-Load (kN) vs. Deflection (mm) data for steel fiber concrete beam without reinforcement at 14 days curing age.

\begin{tabular}{|c|c|c|c|c|c|c|c|c|c|c|}
\hline \multirow{4}{*}{$\begin{array}{c}\text { Load } \\
(\mathbf{k N})\end{array}$} & \multicolumn{10}{|c|}{ Deflection (mm) } \\
\hline & \multicolumn{5}{|c|}{14 days ( AR: 50) } & \multicolumn{5}{|c|}{14 days (AR: 70) } \\
\hline & \multicolumn{10}{|c|}{ Volume fractions (\%) } \\
\hline & $\begin{array}{c}\mathbf{P C} \\
(0 \%)\end{array}$ & $1 \%$ & $1.5 \%$ & $2 \%$ & $2.5 \%$ & $\begin{array}{c}\mathrm{PC} \\
(0 \%)\end{array}$ & $1 \%$ & $1.5 \%$ & $2 \%$ & $2.5 \%$ \\
\hline 0.0 & - & - & - & - & - & - & - & - & - & - \\
\hline 1.9 & N.T. & N.T. & 0.049 & 0.0945 & 0.098 & N.T. & 0.091 & 0.0875 & 0.07 & 0.112 \\
\hline 3.8 & 0.049 & 0.014 & 0.0735 & 0.126 & 0.1505 & 0.049 & 0.126 & 0.1365 & 0.112 & 0.189 \\
\hline 5.6 & Fails & 0.0315 & 0.112 & 0.154 & 0.1925 & Fails & 0.154 & 0.196 & 0.161 & 0.252 \\
\hline 7.5 & & 0.056 & 0.14 & 0.189 & 0.224 & & 0.266 & 0.217 & 0.217 & 0.343 \\
\hline 9.4 & & 0.0875 & 0.1715 & 0.259 & 0.2975 & & 0.294 & 0.245 & 0.266 & 0.448 \\
\hline 11.3 & & 1.26 & 0.2156 & 0.938 & 1.365 & & 0.994 & 0.371 & 0.329 & 1.365 \\
\hline 13.2 & & & 0.273 & & & & & 1.085 & 1.204 & \\
\hline 15.0 & & & 0.966 & & & & & & & \\
\hline
\end{tabular}

$*$ N.T. $=$ Not Traceable

Table-7:- Load $(\mathrm{kN})$ vs. .Deflection $(\mathrm{mm})$ data for steel fiber concrete beam without reinforcement at 28 day curing

\begin{tabular}{|c|c|c|c|c|c|c|c|c|c|c|}
\hline \multirow{4}{*}{$\begin{array}{c}\text { Load } \\
(\mathbf{k N})\end{array}$} & \multicolumn{10}{|c|}{ Deflection (mm) } \\
\hline & \multicolumn{5}{|c|}{28 days ( AR: 50) } & \multicolumn{5}{|c|}{28 days ( AR: 70) } \\
\hline & \multicolumn{10}{|c|}{ Volume fractions (\%) } \\
\hline & $\begin{array}{c}\text { PC } \\
(0 \%)\end{array}$ & $1 \%$ & $1.5 \%$ & $2 \%$ & $2.5 \%$ & $\begin{array}{c}\mathrm{PC} \\
(0 \%)\end{array}$ & $1 \%$ & $1.5 \%$ & $2 \%$ & $2.5 \%$ \\
\hline 0.0 & - & - & - & - & - & - & - & - & - & - \\
\hline 1.9 & N.T. & 0.056 & 0.091 & 0.133 & 0.091 & N.T. & 0.2 & 0.14 & 0.07 & 0.091 \\
\hline 3.8 & 0.042 & 0.112 & 0.14 & 0.1715 & 0.1225 & 0.042 & 0.31 & 0.217 & 0.105 & 0.1855 \\
\hline 5.6 & 0.063 & 0.1365 & 0.1715 & 0.2065 & 0.175 & 0.063 & 0.415 & 0.2905 & 0.1365 & 0.217 \\
\hline 7.5 & Fails & 0.1512 & 0.203 & 0.217 & 0.21 & Fails & 0.48 & 0.336 & 0.1645 & 0.259 \\
\hline 9.4 & & 0.168 & 0.238 & 0.301 & 0.252 & & 0.56 & 0.392 & 0.182 & 0.336 \\
\hline 11.3 & & 0.196 & 0.287 & 0.378 & 0.343 & & 0.64 & 0.448 & 0.273 & 0.385 \\
\hline 13.2 & & 0.2415 & 0.427 & 1.33 & 1.54 & & 1.6 & 1.12 & 0.406 & 0.476 \\
\hline 15.0 & & 1.26 & 0.504 & & & & & & 0.448 & 1.225 \\
\hline 16.9 & & & 0.91 & & & & & & 0.5376 & \\
\hline 18.8 & & & & & & & & & 1.008 & \\
\hline
\end{tabular}

$*$ N.T. $=$ Not Traceable 


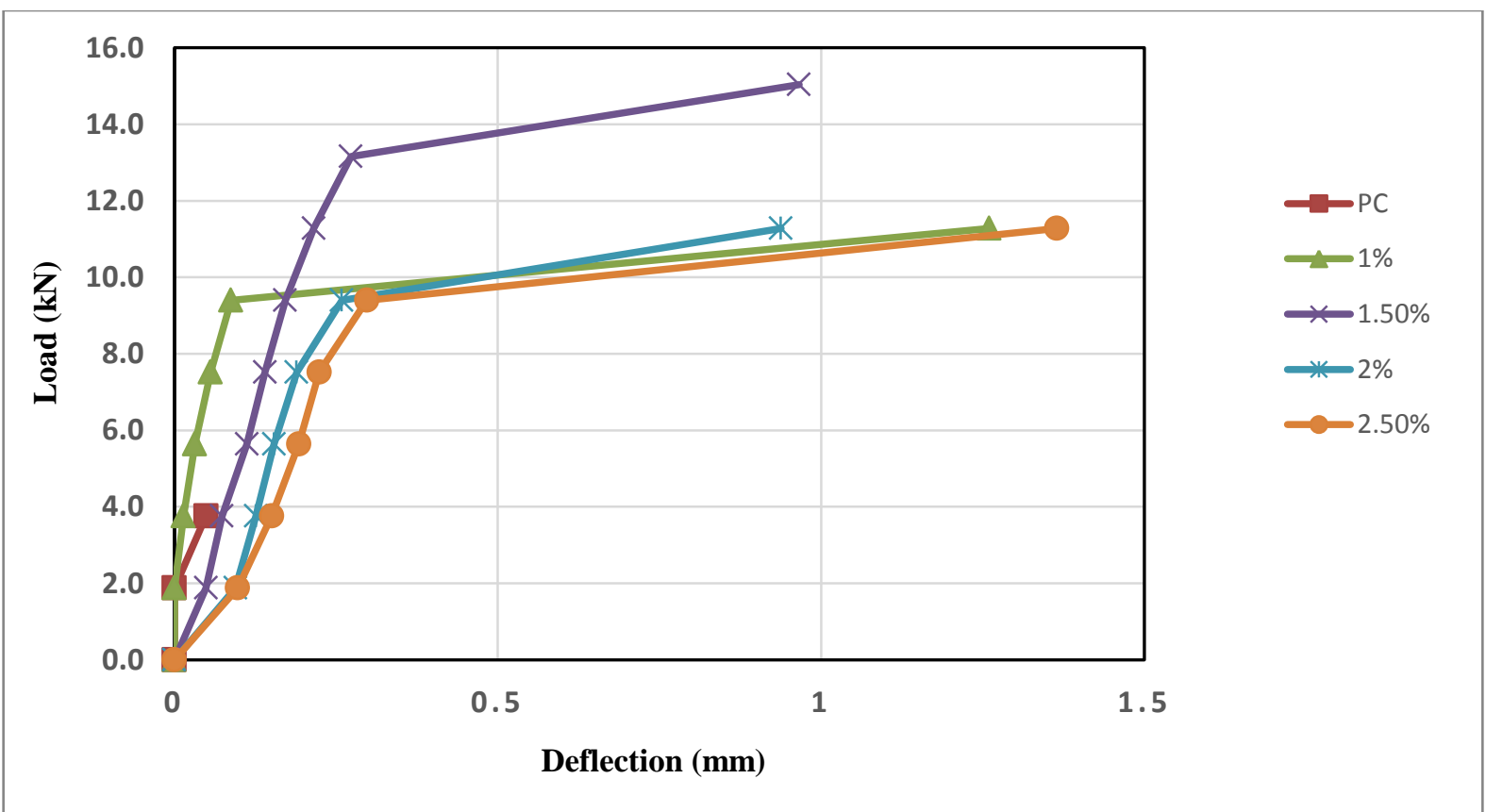

Fig-3:- Load vs. Deflection curve for beam specimens at constant AR:50 (curing age: 14 days)

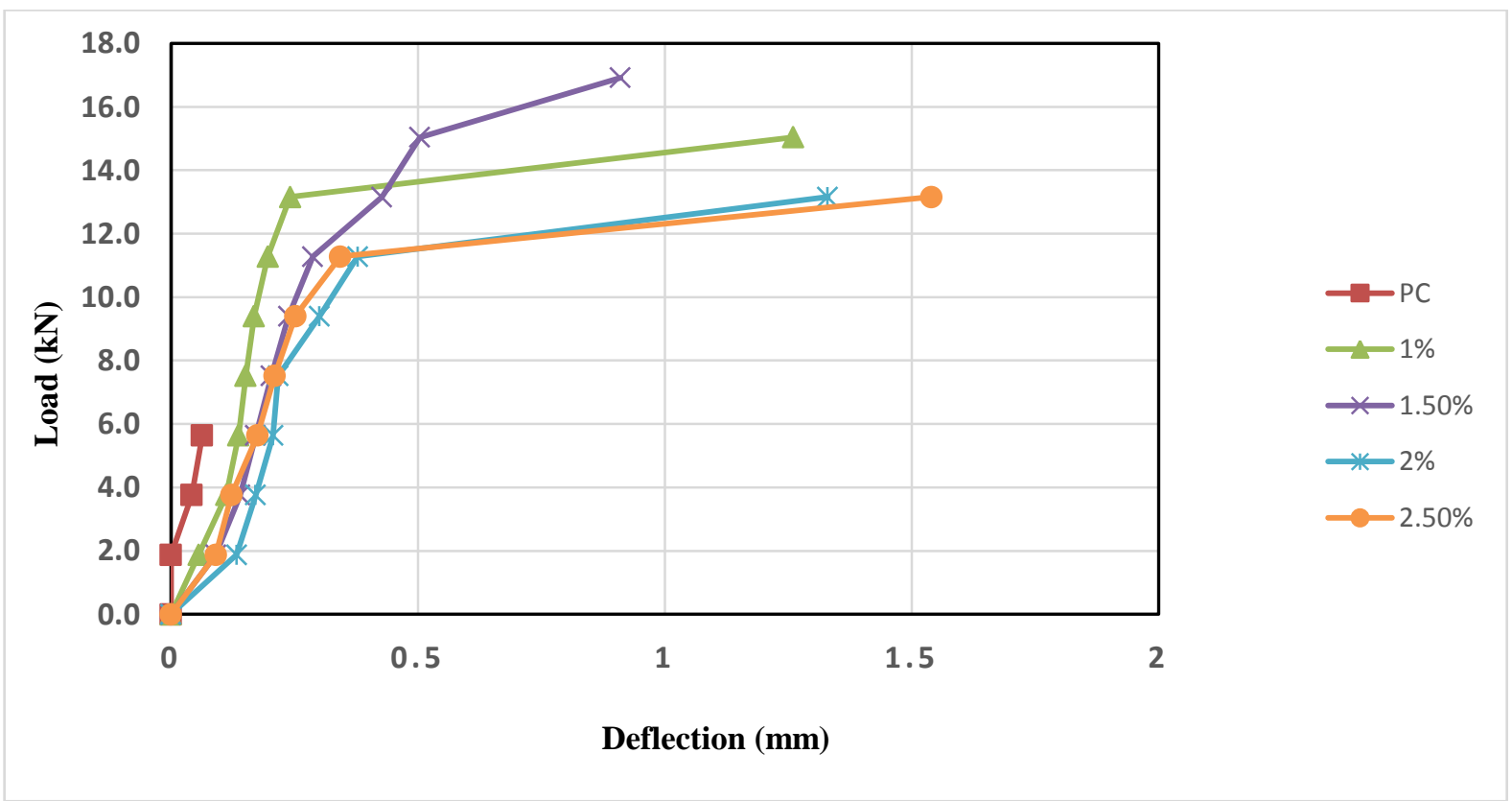

Fig-4:-Load vs. Deflection curve for beam specimens at constant AR:50 (curing age: 28 days) 


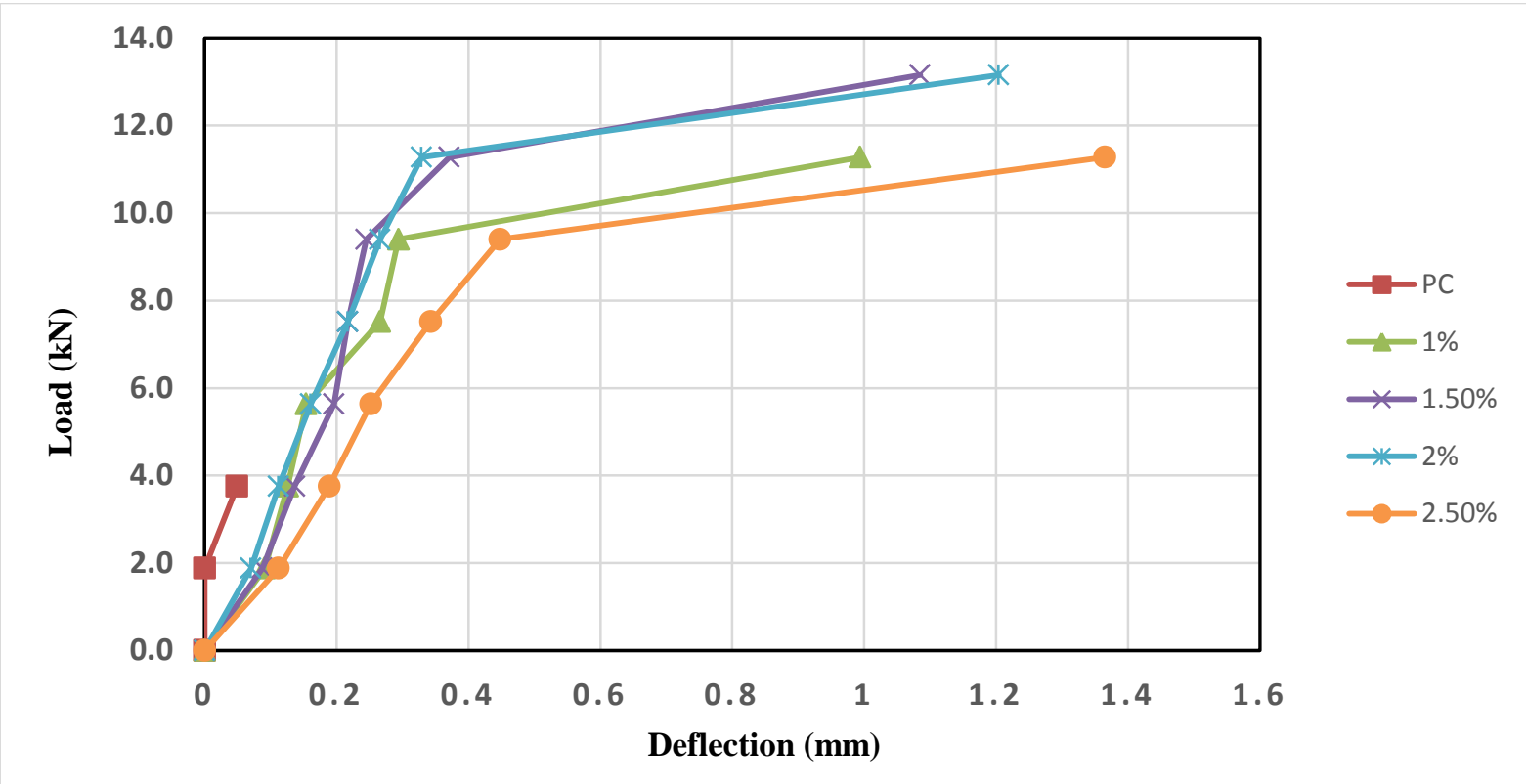

Fig-5:- Load vs. Deflection curve for beam specimens at constant AR:70 (curing age: 14 days)

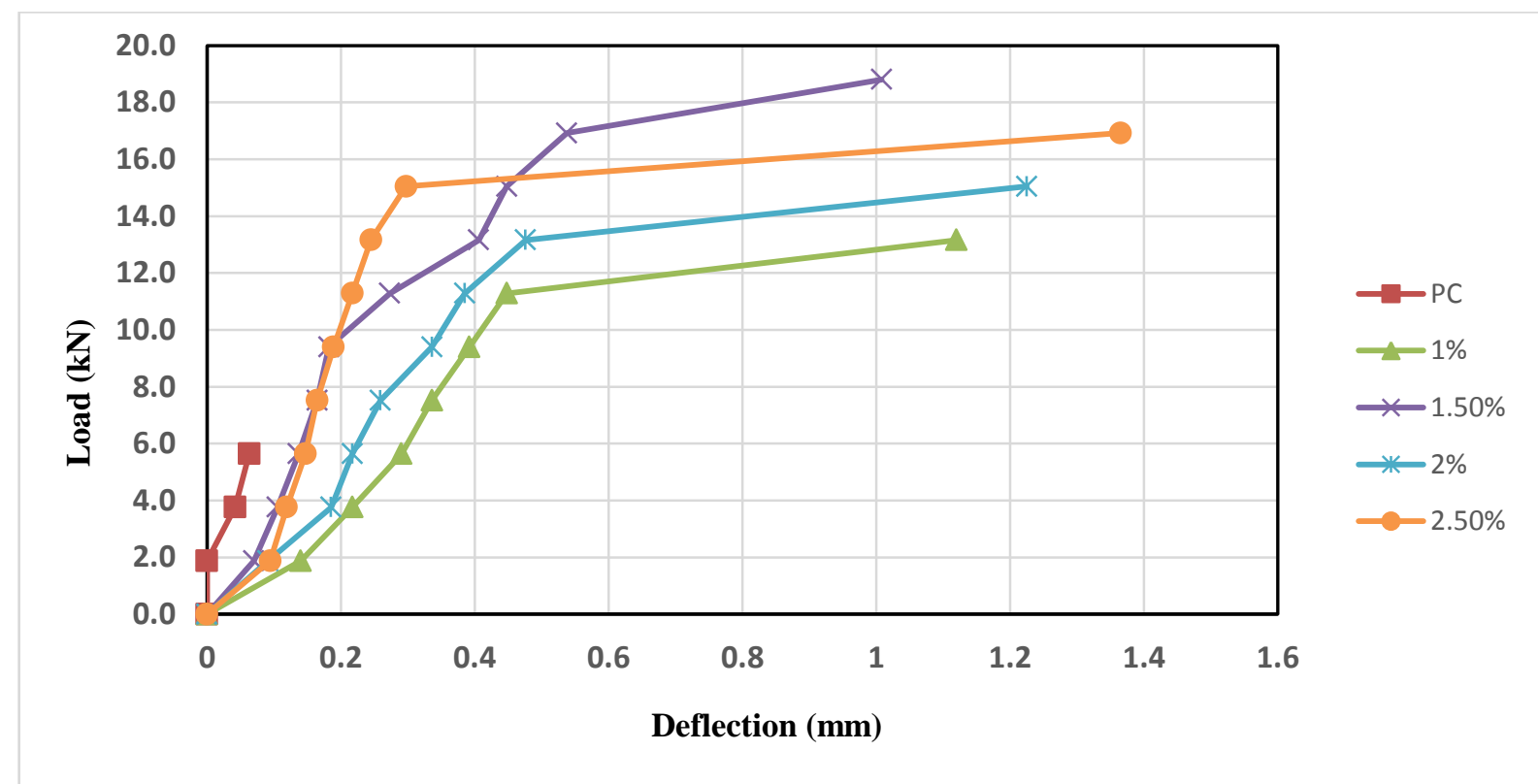

Fig-6:-Load vs. Deflection curve for beam specimens at constant AR:70 (curing age: 28 days)

From the Fig/Table, it is seen that the beam specimens without fiber i.e. the control specimens show negligible deflection and fails suddenly at relatively low loads. Whereas SFRC beam specimens carry significantly higher loads and undergo gradual deflection with the increase of loads depending on the inclusion of steel amount and curing ages. Also, the appearance of cracks in SFRC beams was clear \& distinct stating from hairline cracks to visible ones. This is due to presence of randomly dispersed steel fibers that arrest the cracks effectively in concrete. The short discrete fibers bridge \& delay the propagation of micro cracks. It is also noticed that the ultimate load capacity of SFRC beams increases up to an optimum fiber content (i.e. at $2.0 \%$ ) \& then decreases similar to over reinforced action in RC beams that often leads to a reduction in strength (Ali. A. Abbas et al., 2013). Moreover, the SFRC beams, at ultimate or failure loads, shows continuous deflection/deformation with little or without increase in load. 
Thus the load-deflection information \& the cracking/failure pattern of SFRC beams indicates the improved ductility/toughness as compared to plain concrete which can be considered as its special features under dynamic loading. The effective way of controlling/reducing cracks in SFRC may also encourage its application as structural concrete in aggressive environment.

\section{Conclusion:-}

Based on the limited numbers of variables studied as mentioned in experimental program regarding the strength \& deformation performance of steel fiber reinforced concrete, the following conclusions can be drawn:

1) Both the compressive \& flexural strength of concrete are observed to increase with the inclusion of steel fiber. The improvement depends on the fiber volume fractions and its aspect ratios.

2) The compressive \& flexural strength of concrete enhances up to $1.5 \% \& 2 \%$ of steel fiber content respectively and then decreases with the increase of fiber content. $1.5 \% \& 2 \%$ steel fiber content is found as optimum fiber content for compressive \& flexural strength respectively.

3) After 28 days curing, the increase in compressive strength for SFRC is reported to vary in the range of 4 to $24 \%$ whereas for flexural strength, the corresponding increase varies from 40 to $70 \%$.

4) Both compressive and flexural strength values of SFRC increase with the increase in aspect ratio of fiber. The increase in compressive strength was observed as $6 \%$ as aspect ratio changes from 50 to 70 . In flexural strength, the corresponding value was reported as $11 \%$.

5) The plain concrete beam specimen failed completely at a certain load whereas the beam specimens with steel fiber showed gradual failure and a clear flexural crack. The flexure crack developed in SFRC beam specimens were limited to hair cracks only in most of the cases.

6) The load-deflection characteristics \& cracking/failure pattern of the SFRC specimens indicated to improved ductility over plain concrete. Also inclusion of fibers in concrete are observed to improve its flexural strength more effectively as compared to compressive strength.

\section{References:-}

1. ACI 544.1R (1996). "State-of-the-Art Report on Fiber Reinforced Concrete." American Concrete Institute, Farmington Hills, Michigan.

2. Behbahani, H.P., Nematollahi, B. and Farasatpour, M. (2011). "Steel Fiber Reinforced Concrete: A Review."

3. Shende, A.M. and Pande, A.M. (2011). "Experimental study and prediction of tensile strength for steel fiber reinforced concrete." International Journal Of Civil And Structural Engineering (ISSN 0976 - 4399) Volume 1, No 4.

4. Romualdi, J. and Baston, G. (1963). "Mechanics of crack arrest in concrete with closely spaced reinforcement." Journal of the Engineering Mechanics Division., EM3. Proceedings of the American Society of Civil Engineers, $89,147-168$.

5. Rana, A. (2013). "Some Studies on Steel Fiber Reinforced Concrete." International Journal of Emerging Technology and Advanced Engineering (ISSN 2250-2459. ISO 9001:2008 Certified Journal), Vol-3, Issue 1.

6. Ali A. Abbas, Sharifah M. Syed Mohsin, Demetrios M. Cotsovos and Ana M. Ruiz-Teran (2013). "Shear behaviour of steel-fibre reinforced concrete simply supported beams", Elsevier, Construction and Building Materials, Vol. 43, pp. 544-558.

7. Hameed, R., Turatsinze, A., Duprat, F. and Sellier, A. (2009). "Metallic Fiber Reinforced Concrete: Effect of Fiber Aspect Ratio on The Flexural Properties." APRN Journal of Engineering and Applied Sciences (ISSN 1819-6608), Vol. 4, No. 5.

8. Ann Mary Baby and Reshmi P R (2017). "Improving the Flexural Performance of Concrete Beams Using 2D Steel Fibres" International Research Journal of Engineering and Technology (IRJET) (e-ISSN: 2395 -0056 pISSN: 2395-0072) Volume: 04 Issue: 04.

9. A. Jodeiri and R. Quitalig (2012). "Effect of Steel Fibre on Flexural Capacity of Reinforced Concrete Beam" Journal of Civil Engineering Research, vol. 2, pp. 100-107.

10. Vishal Gadgihalli , MeenaY.R , Sindu\& Raghavendra Prasad Havanje Dinakar (2017). "Analysis Of Properties Of Concrete Using Steel Fibers As Fiber Reinforcement Admixture" International Journal of ResearchGranthaalayah, ISSN- 2350-0530(O), ISSN- 2394-3629(P), Vol.5 Iss.4: RASM.

11. Patil Shweta and Rupali Kavilkar (2014). "Study of Flexural Strength in Steel Fibre Reinforced Concrete" International Journal of Recent Development in Engineering and Technology (ISSN 2347 - 6435) Volume 2, Issue 5. 
12. Abdul Ghaffar, Amit S. Chavhan and Dr.R.S.Tatwawadi (2014). "Steel Fibre Reinforced Concrete" International Journal of Engineering Trends and Technology (IJETT), (ISSN: 2231-5381) Volume 9 No. 15.

13. Amir M. Alani and Morteza Aboutalebi (2013). "Mechanical Properties of Fibre Reinforced Concrete- A Comparative Experimental Study" World Academy of Science, Engineering and Technology, International Journal of Civil and Environmental Engineering Vol:7, No:9.

14. A. Fatih, H. Tefaruk and A. Kamura (2005). "Effects of Steel Fiber Addition on Mechanical Properties of Concrete and RC Beams" Construction and Building Materials, vol. 21, pp. 654-661. 